\title{
Adherence of Tc-99m agents to plastic syringes
}

\author{
Trifon Spyridonidis, MD, ${ }^{\mathrm{a}}$ Theodoros Skouras, MSc, ${ }^{\mathrm{a}}$ and \\ Dimitris J. Apostolopoulos, MD, PhD ${ }^{\mathrm{a}}$ \\ a Department of Nuclear Medicine, University of Patras Medical School, University Hospital of \\ Patras, Patras, Greece
}

Received Aug 22, 2016; accepted Aug 22, 2016 doi:10.1007/s12350-016-0660-7

We read with great interest the paper of Reynolds $\mathrm{SN}$ and Kikut J titled "Adherence of ${ }^{99 \mathrm{~m}} \mathrm{Tc}$-Sestamibi to plastic syringes could complicate efforts in dose reduction in MPI SPECT. ${ }^{, 1}$ In this letter, we report on our own experience regarding residual syringe activity after injecting different Tc-99m-labeled compounds via syringes obtained from different manufacturers, over the last 9 months during which we conducted systemic measurements.

In 470 stress-rest ${ }^{99 \mathrm{~m}}$ Tc-tetrofosmin (MYO$\mathrm{VIEW}^{\mathrm{TM}}$, GE Heathcare, UK) MPI studies, the average residual activity in the syringe after tracer injection was $11.0 \pm 3.1 \%$ (range $6.3-20.8 \%$ ). Similar values were obtained with the use of ${ }^{99 \mathrm{~m}} \mathrm{Tc}$-sestamibi (CARDIOSCAN $\AA$, POLATOM, Poland) in 62 parathyroid studies $(10.3 \pm 2.9 \%$, range $5.7-16.8 \%)$. On the contrary, syringe adherence to other ${ }^{99 \mathrm{~m}} \mathrm{Tc}$-agents $\left(\mathrm{Tc}^{-} \mathrm{O}_{4}\right.$, MDP, DTPA, MAG3, Mebrofenin, Phytate, MAA, and nanocolloid) was consistently low, in the order of 3-4\%. The only exception was ${ }^{99 \mathrm{~m}}$ Tc-DMSA (Technescan ${ }^{\circledR}$ DMSA, Mallinckrodt ${ }^{\mathrm{TM}}$ Medical B.V., Netherlands) used in 95 renal studies, where residual activity was $6.8 \pm 2.7 \%$ (range 3.9-14.6\%). During this 9-month period, we used siliconized syringes from three manufacturers (A: Jiangxi Qingshantang Medical Devices Co. Ltd., B: Jiangsu Webest Medical Product Co. Ltd., C: AnHui Honghyu Wuzhou Medical manufacturer Co. Ltd., all three made in China). The volume of the injected activity was uniformly expanded to $2 \mathrm{~mL}$ in syringes of $2.5 \mathrm{~mL}$. In the case of tetrofosmin and sestamibi, residual activity in syringe provider $\mathrm{C}$ was significantly lower than that of providers A and B
$(7.4 \pm 1.3$ vs $12.3 \pm 2.3, \mathrm{p}<.001)$. This difference was not observed with other radiopharmaceuticals.

Our results are in line with the findings of other investigators regarding certain tracers (tetrofosmin, sestamibi, and DMSA), although the amount of residual syringe activity differs. ${ }^{1,2}$ However, our Human Albumin Macroaggregates preparation (MAASOL, GE Heathcare, Italy) did not show significant syringe adsorption, as reported previously. ${ }^{3}$ Different syringe components' constitution, tracer kits, Tc-99m-specific activity, and time from kit reconstitution to injection may account for these differences. At any rate, in accordance with former recommendations, we emphasize the need for routine measurement of full and empty syringe activity in order to determine the real dose administered to the patient.

\section{Disclosure}

None declared.

\section{References}

1. Reynolds SN, Kikut J. Adherence of Tc-99 sestamibi to plastic syringes could complicate efforts in dose reduction in MPI SPECT. J Nucl Cardiol 2016;23:256-64.

2. Stopar TG, Socan A, Peitl PK. Adsorption of radiopharmaceuticals to syringes: Setting up a reliable protocol for its assessment. Nucl Med Commun 2007;28:951-5.

3. Gunasekera RD, Notghi A, Mostafa AB, Harding LK. Adsorption of radiopharmaceuticals to syringes leads to lower administered activity than intended. Nucl Med Commun 2001;22:493-7.
Reprint requests: Dimitris J. Apostolopoulos, MD, PhD, Department of Nuclear Medicine, University of Patras Medical School, University

Hospital of Patras, Rion, 26504 Patras, Greece; dimap@ med.upatras.gr J Nucl Cardiol 2016;23:1526.

$1071-3581 / \$ 34.00$

Copyright (c) 2016 American Society of Nuclear Cardiology. 